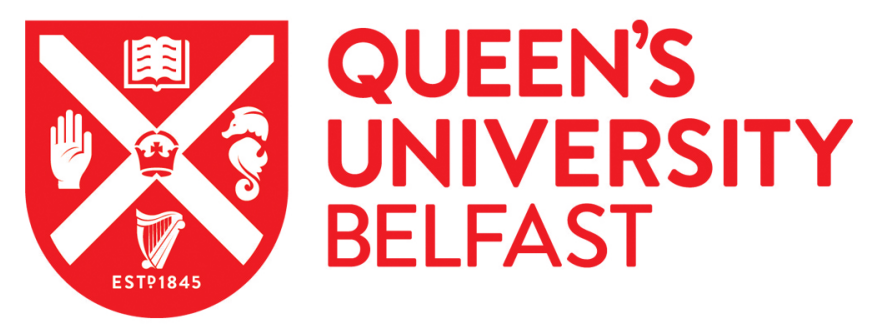

\title{
The experience of individuals with renal failure participating in home haemodialysis: An interpretative phenomenological analysis
}

Cases, A., Dempster, M., Davies, M., \& Gamble, G. (2011). The experience of individuals with renal failure participating in home haemodialysis: An interpretative phenomenological analysis. Journal of Health Psychology, 16(6), 884-894. https://doi.org/10.1177/1359105310393541

Published in:

Journal of Health Psychology

Document Version:

Peer reviewed version

Queen's University Belfast - Research Portal:

Link to publication record in Queen's University Belfast Research Portal

Publisher rights

Copyright 2011 The Authors.

This work is made available online in accordance with the publisher's policies. Please refer to any applicable terms of use of the publisher.

\section{General rights}

Copyright for the publications made accessible via the Queen's University Belfast Research Portal is retained by the author(s) and / or other copyright owners and it is a condition of accessing these publications that users recognise and abide by the legal requirements associated with these rights.

Take down policy

The Research Portal is Queen's institutional repository that provides access to Queen's research output. Every effort has been made to ensure that content in the Research Portal does not infringe any person's rights, or applicable UK laws. If you discover content in the Research Portal that you believe breaches copyright or violates any law, please contact openaccess@qub.ac.uk. 
Home Haemodialysis Users' Experience

RUNNING HEAD: Home Haemodialysis Users' Experience ARTICLE TYPE (SECTION HEAD): ORIGINAL RESEARCH

The experience of individuals with renal failure participating in home haemodialysis: An interpretative phenomenological analysis

\begin{abstract}
Alejandra Cases ${ }^{\text {ab* }}$, Martin Dempster ${ }^{\mathrm{b}}$, Mark Davies $^{\mathrm{c}}$, and Gary Gamble ${ }^{\mathrm{d}}$ ${ }^{a}$ Clinical Psychology Department, Downshire Hospital, South Eastern Health and Social Care Trust, Downpatrick, BT30 6RA, UK; ${ }^{b}$ School of Psychology, The Queen's University of Belfast, Belfast, BT9 5BP, UK; ${ }^{c}$ Department of Clinical Psychology, Belfast City Hospital, Belfast Health and Social Care Trust, Belfast, BT9 7AE, UK;

${ }^{d}$ Causeway Hospital, Northern Health and Social Care Trust, Coleraine, BT52 1HS,
\end{abstract} $U K$. 
Home Haemodialysis Users' Experience

\begin{abstract}
This study explored the experience of individuals with renal failure undertaking home haemodialysis (HHD). Semi-structured interviews were conducted with 6 participants who were active HHD users in a UK region. Participants' accounts were transcribed verbatim and analysed using an interpretative phenomenological approach. Three main themes were identified: (1) embracing treatment and lifestyle freedom and flexibility; (2) re-establishing a sense of self and preferred self-identity; and (3) integrating aspects of active engagement and aspects of supported, life-sustaining dependence. A 'good fit' between the HHD user (an independent, self-determined health participant) and the healthcare provision (personalised, enabling) is proposed.
\end{abstract}

Keywords: Home haemodialysis, users' experience; qualitative study; interpretative phenomenological analysis 


\section{Introduction}

Established renal failure (ERF), also known as end-stage renal failure or disease, refers to the irreversible loss of kidney function requiring renal replacement therapy to sustain life. The two main treatment options available to individuals with this chronic condition are kidney transplantation and dialysis. Haemodialysis is the most commonly used dialysis treatment in the UK, involving the artificial process of removing waste products and excess fluid from the blood using a machine with a dialyser. Haemodialysis treatment typically requires thrice-weekly schedules lasting 4 hours each (UK Renal Association, 2007), provided by health professionals in a hospital or community-based centre. Home haemodialysis (HHD), is a self-treatment option undertaken by individuals at home.

The National Institute for Clinical Excellence has published guidelines recommending that the option of HHD should be offered to suitable individuals (NICE, 2002). However, despite mounting evidence on the cost-effectiveness of this modality (Gonzalez-Perez, Vale, Stearns, \& Wordsworth, 2005), and improved quality of life and survival rates for HHD users (Mowatt, Vale \& MacLeod, 2004), the utilisation of HHD in the UK remained at only $1.1 \%$ among all patients requiring renal replacement therapy in 2007 ; representing $2.4 \%$ of the haemodialysis population (Ansell et al., 2008). Nonetheless, as more user-friendly technology and newer HHD regimes are being developed, the use of HHD is predicted to increase (Blagg, 2008).

Living with the life-threatening and chronic nature of ERF, and the demanding renal treatment regimes required to sustain life (dialysis combined with medication, diet and fluid restrictions) presents the individual with numerous psychosocial and health-related challenges, including ongoing medical complications and co-occurring psychopathology to manage or negotiate (Kimmel \& Peterson, 2005). Potential 
stressors of living with ERF and haemodialysis include "dietary and time constraints, functional limitations, loss of employment, changes in self-perception, alterations in sexual function, general and perceived effects of illness, medications used to treat the illness, and fear of death" (Kimmel, 2001, p. 1600).

Previous research indicates that engaging in home-based, medical technology assisted treatment for chronic conditions can have a negative impact on individuals' social functioning (Lehoux, 2004). Among patients with ERF, there is evidence to suggest that users of continuous ambulatory peritoneal dialysis (a home-based treatment) have poor quality of life (Lindqvist \& Sjödén, 1998). In this context, the importance of attending to the experience of living with ERF and dialysis from the individual's perspective has been increasingly recognised; resulting in a proliferation of studies addressing diverse aspects of the individual's life-world. Areas of qualitative enquiry have included the experience of living with ERF, dialysis treatment and technology (Faber, de Castell \& Bryson 2003); the coping, selfmanagement and adjustment experience (Curtin, Mapes, Petillo \& Oberley, 2002); and the experience of hope, morality and spirituality (Dekkers, Uerz \& Wils, 2005; Tanyi \& Werner, 2008a). A literature review on the user's perspective of living with different dialysis modalities conducted by Polascheck (2003b) concluded that individuals face a complex situation: managing their own concerns regarding the condition and its treatment in the context of the renal setting or healthcare system.

Themes reflected in the qualitative study of living with in-centre haemodialysis have captured the experience of 'suffering', such as loss of freedom and increased dependence (Hagren, Pettersen, Severinsson, Lützén \& Clyne, 2001); 'bodymachine struggles' (individuals feeling depersonalised or 'objectified' whilst the dialysis machine becomes humanised: Nagle, 1998; Smith, 1996); and an 'existential 
struggle' as treatment encroaches on the individual's time and space (Hagren et al., 2005). Authors have begun to identify factors contributing to the ongoing process of adjusting and re-adjusting (active self-management, hope, spirituality and family support) that centre-based haemodialysis users report experiencing over time (Tanyi \& Werner, 2008b; Walton, 2002).

Reported advantages of home self-treatment have been based on clinical experience/professional 'wisdom' (Agar, 2008; Masterson, 2008), and users' testimonies (Stuempges, 2006; Weintraub, 2004). However, very few qualitative studies have purposely addressed, from the individual's perspective, the unique personal experience of individuals undertaking the specific modality of HHD. Giles (2003, 2005) explored the 'lived-world' of 4 individuals in relation to the dialysis machine and, in line with the literature on the experience of in-centre modalities of renal replacement therapy, identified 'struggles' between the lived-body (becoming 'objectified') and the life-sustaining haemodialysis machine (becoming 'humanised'). On the other hand, Polaschek (2003a, 2005) explored 6 men's experience of haemodialysis self-treatment and described 4 main themes of their discourse. Two themes referred to the perceived benefits of HHD in terms of symptom management and lifestyle ('managing haemodialysis at home' and 'negotiating dialysis into their lifestyle'); and the other two tapped into concerns about ongoing uncertainty and dependence with an emphasis on coping ('managing uncertainty in living on dialysis' and 'coping with becoming more dependent when living on dialysis').

The present study aims to gain insight into the subjective experience of individuals living with HHD, rather than focusing on the dialysis technology or aspects of self-care. Thus, in the context of UK recommendations to facilitate haemodialysis treatment choice for suitable individuals (NICE, 2002), this research 
seeks to contribute to the understanding of HHD users' life-worlds by exploring the lived-experience of a group of individuals from a UK region.

\section{Method}

Participants in this study were HHD users. At the time of the study being conducted, 21 individuals in the region had undertaken HHD training, of whom 14 (12 males and 2 females) remained active HHD users. A sample of 6 individuals participating in HHD (age range $=48-74$, mean age $=60, \mathrm{SD}=10.6$ ) were recruited.

At the time of recruitment, the study participants ( 5 male and 1 female) were married ( 1 became subsequently widowed). Five were retired professionals and one was in part-time employment. Participants had been diagnosed with ERF for between 2 and 24 years $($ mean $=9.8$ years, $\mathrm{SD}=7.4)$. The study group had been using HHD for a period ranging between 2 months and 5 years (mean $=2.3$ years, $\mathrm{SD}=2.2$ ), and their HHD treatment regime comprised 3 to 4 treatment schedules and a total of 10.5 to 24 actual dialysis hours per week $($ mean $=14.25, \mathrm{SD}=4.66)$. All participants had previously undertaken hospital haemodialysis for a length of time ranging between 8 months and 5 years (mean time $=3.16$ years, $\mathrm{SD}=1.72$ ). In addition, 3 individuals had had previous kidney transplants and all but one participant were on the transplantation waiting list.

The research protocol was approved by a regional NHS Research Ethics Committee. All individuals participating in the HHD programme in the region were considered suitable for inclusion in the study. Potential participants were approached by the HHD programme lead-nurse and offered information about the study before considering taking part. All 6 initially approached individuals agreed to participate. 
Semi-structured interviews were conducted, using as a guide an interview schedule adapted from a previous study by Smith (1996; reported in Smith \& Osborn, 2003, pp. 58-59). The schedule covered three broad areas: (i) the experience of starting HHD; (ii) the impact of HHD treatment on self, coping and lifestyle; and (iii) the experience of healthcare and support systems whilst on HHD. However, the interviews allowed participants to spontaneously raise issues important to them

Five interviews took place in the offices of the hospital clinical psychology department and one was carried out at the participant's home. Interviews lasted between 60 and 90 minutes each, and were audio-recorded and later transcribed verbatim. All participants agreed to further contact to provide feedback on the summary themes produced from their individual transcript analysis.

Participants' accounts were analysed using interpretative phenomenological analysis (IPA) (Smith \& Osborn, 2003). The use of IPA is particularly relevant to research concerned with exploring individuals' experience of health and illness (Brocki \& Wearden, 2006); and to current UK NHS emphasis on acknowledging and listening to service users (Reid, Flowers, \& Larkin, 2005).

An idiographic multiple-case study approach to analyses was adopted, described by Smith (2004, p. 41) as a process that: (i) starts with "the detailed examination of one case until some degree of closure or gestalt has been achieved"; (ii) continues with "a detailed analysis of the second case, and so on through the corpus of cases"; and (iii) moves onto "an attempt to conduct a cross-case analysis." A reflective diary was maintained throughout the study, as a way of monitoring how the researcher's thought processes changed over time, particularly throughout the analysis and interpretation stages (reflexive validity). 
Participants' feedback was sought after all transcripts had been individually analysed, before shared themes were explored, and consisted of an informal talk (either in person or on the phone) between AC and each individual on their transcript's themes, lasting on average 30 minutes. This process of validation was adopted as an opportunity to gather feedback on the findings derived from individuals' accounts (see Willig, 2001), which helped further stimulate the researcher's reflexivity. Participants agreed with the description of their own transcript themes (testimonial validity). In addition, two other members of the research team, contributed to the credibility checks at the initial stage of analysis (stages 1 and 2) by scrutinising and generating themes for one transcript. Their input at this stage served the function of an audit (to check that the analysis was grounded in the data and thus credible), provided new interpretative perspectives on the analysis, and aided the reflexivity process. These members of the research team were also involved in the process of arriving at the main themes and their interpretation (consensus validity).

\section{Findings}

Three main themes were identified, representing shared aspects of the 6 participants' experience of living with HHD: (1) embracing treatment and lifestyle freedom and flexibility; (2) re-establishing a sense of self and preferred self-identity; and (3) integrating aspects of active engagement and aspects of supported, life-sustaining dependence (See Table 1).

Insert Table 1 about here 


\section{Embracing treatment and lifestyle freedom and flexibility}

Participants talked enthusiastically (and without prompts from the interviewer) about their experience of perceived gains or benefits from undertaking HHD, which contrasted with their recollection of having previously experienced hospital haemodialysis treatment as a more restrictive option. These benefits included a sense of gained or freed-up time and enhanced flexibility to organise treatment to suit the person's lifestyle:

So the great thing about dialysing at home is that: (1) as I say, you don't have to travel [...] (2) you've the flexibility of deciding at what time of the day to suit your lifestyle [...] What you're basically doing is, you're building the dialysis around your life, you're not building your life around the dialysis, so it's giving you more flexibility [...] (Ryan, 4: 1621).

With this flexibility, participants appeared to derive a sense of freedom to choose when, how, for how long to do their treatment and to engage in non-health-related activities, as desired:

Before, your whole day was taken up with [...] coming to [hospital] [...], going home and sleeping; whereas now [...] you're not being held back by having to go on the machine [...] We just get on with life [...] it means a life where we are out on different things, you know (Catriona, 7: 309)

\section{Re-establishing a sense of self and preferred self-identity}

Participants reported on further perceived personal gains of moving from hospital to home self-treatment, and spoke about this transition as a process of re-constructing their preferred view of self by means of gaining a greater sense of autonomy and control (a term spontaneously introduced by participants) over their treatment, health, and life in general: 
Home Haemodialysis Users' Experience

Well, you know, eh, the nurses are great. I couldn't speak highly enough of the nurses in the Unit. They are terrific. But, eh, I don't like to depend on anybody, really [...] Having my kidneys removed $[\ldots]$ was a big blow to my way of life, eh. So, eh, getting back to my own control, I've kind of re-instated some of that. Yeah (Michael, 6: 286).

Furthermore, this process entailed a chance to shift or re-order life priorities, with personal ones gaining importance over medical ones; as participants' preoccupation with and concerns about treatment eased through their improved sense of health and well-being while on HHD. Thus, participants appeared to have re-established their identity as healthy or 'well' individuals and spoke about themselves in terms of the personal roles (in relation to self and others) and the life pursuits that they identified with:

[When on hospital HD] you were away from home, and my daughter and I grew apart during that time, because I was never there for her $[\ldots]$ and only through the home haemo we have got back together again, [...] and we have a life together (Catriona, 2: 81).

It's made lots of changes from the point of view that I can go out with my wife or out with my friends, and if I know I'm going to go out on a certain night, I just make sure I do dialysis that day (George, 18: 821).

All but one participant spoke about themselves as healthy individuals since commencing HHD (as opposed to being a 'patient' with a chronic physical condition or undergoing a medical treatment):

No, I was never content whenever I was a patient, never. You know, it was a toil [...]

(Catriona, 10: 453). 
Home Haemodialysis Users' Experience

Frank, on the other hand, expressed having found it useful to adopt a view of self as a 'patient' (versus a professional 'expert'). However, for Frank (as for the other HHD users in the study) participating in HHD had also facilitated his engagement in personal priorities and his chosen lifestyle:

Well $[\ldots]$ we're looking after our granddaughter, eh, and that, eh, influences what time we go on it [HHD] [...] [I like] my own space [...] I was very glad to get out of there [the hospital] (Frank, 6: 273; 11: 535).

Overall, what appeared to be implicit in HHD users' accounts of experience whilst participating in HHD was a restored sense of 'wellness' and 'normality' through the adoption of preferred ways of 'being' (in relation to self and others). Thus, the reestablishment of a sense of autonomy and control (together with a return to the individual's personal routine and priorities) seemed to be facilitated by the move from a hospital environment (which might have elicited a more 'passive' stance for participants, as individuals in receipt of medical treatment) to the individuals' home setting (where they perceived themselves as 'able' individuals and active life participants):

My home life, you know, eh, that's more important to me than anything, you know. I'm quite content the way I am. Nothing costs me a thought anymore. I'm not as worried [...] We really hadn't got a life, we really hadn't got a life before this (Catriona, 18: 871; 885). 
Home Haemodialysis Users' Experience

Integrating aspects of active engagement and aspects of supported, life-sustaining dependence

Aspects of active engagement (independent self-care, ownership)

Participants described the period of getting used to their responsibility for treatment as an initially 'daunting' experience, which became easier over time:

I remember that most vividly, the very first day when I had the machine installed in the house and there was no nurse there. And I remember, I must have sat for about 5 minutes, you know, with this needle in my hand, saying, 'I've got to do this and there's nobody here if anything goes wrong.' But that, everybody has to get over that, you know, that goes [...] (Ryan, 9: 440).

They appreciated having been able to undergo training to prepare for HHD and build up confidence and skills in the use of the equipment; and having been involved in decisions regarding 'readiness' for self-treatment:

The decision to actually take everything to the house was mine, it wasn't any of the hospital staff or that, it was my decision, 'right, I feel ready to do it' (David, 28: 1330).

The HHD treatment itself, a lengthy process involving new responsibilities and active doing (such as learning about the workings of the dialysis machine), was described by HHD users as an established routine. This was possibly facilitated by a positive reframing of the treatment at home as advantageous for the individual:

Even though it takes longer, it takes me like a, it takes an hour to set the machine up, to line the machine, and to heat disinfectant and all the rest of it [...] But it doesn't really matter because you're doing it yourself and you know when you can do it, you know how you can do it (Michael, 13: 641). 
Participants spoke about themselves as independent agents. They attributed perceived health improvements to their actions through self-treatment, as facilitated by both the possibility of more frequent dialysis and their ability to optimise their health through a self-initiated, individualised approach to their treatment regime:

The other thing about dialysing at home is that you can do more hours [...] So, the more treatment that you're getting, the better the quality of [dialysis]. Obviously, your blood is cleaner and you're not carrying the same toxins, and your well-being should be a lot better because you're getting better dialysis (Ryan, 3: 124).

You can manipulate it yourself. You can, you know, take the flow up, take the flow down, if you understand it; and you can adjust the needles [for a fuller dialysis] (Frank, 21: 1033).

A sense of satisfaction (from the ability to self-manage treatment and to actively problem solve), and ownership (over improved health status) emerged from the data; which contrasted with a less satisfying and more passive stance that participants felt they had experienced when their HD treatment had been provided for them in hospital:

I know what I'm doing, and I like doing what I'm doing. I almost enjoy putting myself on dialysis [...] I just like to know that I can do this, you know [...] I get enjoyment out of doing it correctly [...] I have myself in good order because of me; with a, with a great team of people working with me. Whereas if I was in the hospital [...] it would be somebody else who'd done all that, you know. It's me who's doing it (Michael, 17: 830). 
Home Haemodialysis Users' Experience

Aspects of supported, life-sustaining dependence

Participants referred to the perceived restrictions of living with ERF and

haemodialysis treatment, with an emphasis on how they cognitively and behaviourally integrated such elements of dependence. Participants talked about dependence on the machine:

Whether you are at home or whether you are up in the Unit, you are still stuck to the machine.

There is nothing you can do [...] You realise that there is no point fussing about it [...]

(David, 5: 202; 232).

The only, the only downside about home dialysis is the efficiency and the reliability of the machine $[\ldots]$ But, nevertheless, it's, it's something I'm prepared to put up with, as long as I can continue with the home dialysis (Michael, 2: 71).

In addition, they highlighted their dependence on medical (for blood results as evidence of treatment efficacy) and technical (for the maintenance of the machine) support teams:

You sort of wonder, at times [...] did the dialysis really work, did that session work? You know, apart from, apart from the weight loss with the excess fluid coming off, you can't tell from the machine how well your dialysis has went. You're depending on blood samples (David, 9: 398).

Finally, whilst two participants chose to dialyse without a home 'presence', the majority indicated their dependence on personal helpers:

I don't think I would do [the dialysis] if I was the only one in the house [...] I'm quite happy to sit in the room on my own and do it knowing that there is somebody else there [...] I think it's the sensible thing, you know, knocking about with arteries (David, 32: 1521). 
Home Haemodialysis Users' Experience

\section{Integration of aspects of independence and dependence}

The study participants seemed able to integrate (or at least not be overtly preoccupied with) the elements of the ERF condition and life-sustaining treatment they were unable to change (dependence on the use of the dialysis machine for survival); whilst actively embracing those aspects of ERF and HHD that were potentially 'controllable' through self-treatment (learning about the workings of the machine to optimise treatment):

If your attitude is right, I've got a, I've got a problem. I have a renal disease; but there's ways around it. I can go to dialysis, and if I keep the, the diet, I, I stick to the diet, and I do my treatment, and I take the medication, eh, I can make a better quality of life for myself. And in fact, if I do it at home I can even make things better again, because I can spend more time with my family, I can do more dialysis, I'll feel better. [...] I'm here today, I'm healthy, I'm gonna enjoy life, and I'm gonna get on with it (Ryan, 23: 1102).

In other words, a 'good fit' appeared to exist between the individuals' preferences and priorities and their chosen treatment modality:

Everybody should be offered [home HD]. I think it's fantastic. I would sing its praises dear and daily. But it's not for everybody. If you have the right frame of mind, it's great. [...] From a mental health point of view, eh, if you do things right, you'll feel better health wise and you'll feel better mentally as well [compared to when on hospital HD] (Ryan, 29: 1409).

\section{Discussion}

Three shared themes were identified from HHD users' accounts, referring to their experience of health-related and personal gains from participating in HHD ('embracing treatment and lifestyle freedom and flexibility', 're-establishing a sense of 
self and preferred self-identity'); and aspects of adjustment to life with ERF and HHD ('integrating aspects of active engagement and aspects of supported, life-sustaining dependence').

The study participants expressed a positive view of HHD as it facilitated treatment and lifestyle flexibility, choice, freedom, control, compared to their previous experience of hospital-based haemodialysis. In addition, participants presented as having an active, purposeful, and self-directed approach to their home treatment (via the use of self-management skills), with a dual health and personal goal: to improve and/or maintain their health and wellbeing, and their chosen lifestyle and self-identity. Thus, for our study group, a 'good fit' between the modality of HHD and the individuals' preferred self-management approach towards both healthcare and everyday life appeared to facilitate the integration of the less 'controllable' (dependent) and the more 'controllable' (autonomous) aspects of living with ERF and haemodialysis.

The study findings clearly contrast with themes of 'struggles' (of living with a 'dehumanising', 'depersonalising' dialysis machine; Nagle, 1998; Smith, 1996); and 'suffering' (as a result of loss of freedom, dependence on the machine or reliance on carers; Hagren et al., 2001) depicted in the literature on the experience of in-centre haemodialysis treatment. Interestingly, however, Hagren et al. (2001) noted that dialysis users' 'suffering' could be alleviated with increased autonomy and 'acceptance' of dependence (elements captured by the present study's third theme).

On the other hand, the findings are consistent with the themes of HHD livedexperience reported by Polaschek (2003a, 2005). In Polaschek's study, participants reported perceived advantages of the HHD modality over in-centre haemodialysis (increased control and comfort 'managing haemodialysis at home' and integrating or 
'negotiating dialysis into their lifestyles'), whilst they shared "the concerns common to all people living on dialysis" (managing uncertainty and coping with dependence) (2005, p. 29). Moreover, participants in the present study described the elements of dependence on the machine (and other dependent aspects of treatment) as an integral and non-problematic part of their experience. Thus, other more controllable aspects of living with ERF and HHD, together with their chosen lifestyles and regained sense of self, came to the fore in their accounts of experience. From participants' descriptions of living with HHD, the process of integrating different aspects of lived-experience appeared to have a central component: their perceived ability to continue to exert selfdirection in the management of their health and their day-to-day life.

Themes of perceived control, independent self-care and active selfmanagement have been linked to issues of 'empowerment' in healthcare (e.g., Curtin, Mapes, Schatell \& Burrows-Hudson, 2005), with an emphasis on enabling individuals (who are able and/or willing) to take an active role in the management of long-term conditions (Department of Health, 2005, 2008). Authors such as Salmon and Hall (2003, 2004) proposed that, in many instances, user empowerment in health and illness management "is a product of professional and academic discourse rather than of patients' own aspirations or experience" (2003, p. 1976). Thus, warning of the risk of shifting responsibility from health professionals to the individual. Yet, a recent review on the effectiveness of empowerment strategies to improve health, including the management of ERF (Tsay \& Hung, 2004), described these as 'promising' (Wallerstein, 2006). Of particular relevance is a literature review on the issue of empowerment in renal, other health settings and nursing conducted by Tims, King and Bennett (2007) which distinguished 7 "major elements of empowerment: selfdetermination, partnership, effective communication, goal setting, socio-political 
awareness, a caring environment and construction of knowledge" (2007, p. 53). Only two relevant studies on empowerment and ERF were identified, both exclusively addressing the component of self-determination (see Tims et al., 2007).

In our study, whilst participants acknowledged the necessary support that they had required to initiate (and continued to require to maintain) HHD, their accounts appeared to highlight their own motivation, willingness and commitment to optimise their health status and quality of life, as lying behind their choice and ability to use HHD. Similarly, participants expressed ownership for their perceived positive 'consequences' or advantages of managing ERF by using HHD. Thus, whilst we could hypothesise that other issues such as partnership and health provider-user collaboration influenced how HHD users experienced and made sense of living with this treatment modality, the central component of empowerment expressed by participants was self-determination or empowerment from within.

HHD users presented as independent, self-empowered health participants who appreciated and/or required personalised and supportive healthcare provision. This is relevant to clinical practice in that a personalised approach to the management of the chronic condition of ERF (including attending to the individual's changing psychological needs) and the availability of tailored maintenance treatment options for different individuals should be considered by service providers. The ongoing availability and development of HHD programmes, incorporating users' views, attending to issues of lived-experience, and facilitating relevant support resources, is recommended.

Given the nature of the study sample, the findings need to be considered within the specific context in which the individuals' accounts of lived-experience were situated. 
HHD treatment modalities require a period of training and health stabilisation. As a result, individuals often experience other treatment options, mostly hospital haemodialysis, before commencing self-treatment. Whilst, in the current climate of HHD under-utilisation, attaining a sample of participants on HHD as their first treatment modality might prove difficult, addressing users' experience of HHD from the crucial point of diagnosis remains a pertinent area for future qualitative enquiry. Similarly, prospective studies exploring users' experience of the transition from centre-based to home self-treatment might aid our understanding of the impact of treatment choice on the individuals' perceived well-being and quality of life.

Finally, whilst participants' emphasis on a positive/helpful experience of HHD is viewed as reflective of their perception of this treatment modality (particularly in the context of their previous experience of in-centre haemodialysis); it is nevertheless possible that they might have chosen to portray a positive image of their experience of using HHD. For instance, as a way of expressing gratitude for the service received; ensuring that this treatment option remained available; or given the small number of HHD users in the region, preventing potentially identifiable information being known to service providers.

In the context of HHD users remaining a small and highly selective group in the UK, our study findings add to the growing body of evidence that, in the absence of kidney transplantations (or suitability of these) for all, some individuals with ERF might find it beneficial to choose to become active participants in their own dialysis self-treatment at home. Thus, while HHD is clearly not for everyone, its uptake has been viewed as a positive development by the group of dialysis users participating in this study. 
Home Haemodialysis Users' Experience

\section{Notes}

1. All participants' names are pseudonyms. Participants' quotations are referred to by the page and line number/s where they are located within individuals' transcripts (e.g., 4: 162 indicates page 4, line 162).

\section{References}

Agar, J.W.M. (2008). Home hemodialysis in Australia and New Zealand: Practical problems and solutions. Hemodialysis International, 12(Suppl. 1), S26-S32.

Ansell, D., Feehally, J., Fogarty, D., Tomson, C., Williams, A.J., \& Warwick, G. (Eds.) (2008). UK Renal Registry report 2008. Bristol, UK: UK Renal Registry. Retrieved May 27, 2009, from http://www.renalreg.com/ Reports/2008.html.

Blagg, C. (2008). The renaissance of home hemodialysis: Where we are, why we got here, what is happening in the United States and elsewhere. Hemodialysis International, 12(Suppl. 1), S2-S5.

Brocki, J.M., \& Wearden, A.J. (2006). A critical evaluation of the use of interpretative phenomenological analysis (IPA) in health psychology. Psychology \& Health, 21(1), 87-108.

Curtin, R.B., Mapes, D.L., Petillo, M., \& Oberley, E. (2002). Long-term dialysis survivors: A transformational experience. Qualitative Health Research, 12(5), 609-624.

Curtin, R.B., Mapes, D., Schatell, D., \& Burrows-Hudson, S. (2005). Selfmanagement in patients with end stage renal disease: Exploring domains and dimensions. Nephrology Nursing Journal, 32(4), 389-395. 
Home Haemodialysis Users' Experience

Dekkers, W., Uerz, I., \& Wils, J.P. (2005). Living well with end-stage renal disease: patients' narratives interrupted from a virtue perspective. Ethical Theory and Moral Practice, 8(5), 485-506.

Department of Health (2004). The National Service Framework for renal services. Part one: Dialysis and transplantation. London: Department of Health/Stationery Office. Retrieved April 7, 2009, from http://www.dh.gov.uk/en/Publicationsandstatistics/Publications/Publications PolicyAndGuidance/DH_4070359.

Department of Health (2005). The National Service Framework for long-term conditions. London: Department of Health/Stationery Office. Retrieved March 3, 2009, from http://www.dh.gov.uk/en/Publicationsandstatistics/Publications/ PublicationsPolicyAndGuidance/DH_4105361.

Department of Health (2008). Raising the profile of long term conditions care: A compendium of information. London: London: Department of Health/Stationery Office. Retrieved April 7, 2009, from http://www.dh.gov.uk/en/Publicationsandstatistics/Publications/Publications PolicyAndGuidance/DH_082069.

Faber, S., de Castell, S., Bryson, M. (2003). Renal failure: Toward a sociocultural investigation of an illness. Mind, Culture and Activity, 10(2), 143-167.

Giles, S. (2003). Transformations: A phenomenological investigation into the lifeworld of home haemodialysis. Social Work in Health Care, 38(2), 29-50.

Giles, S. (2005). Struggles between the body and machine: The paradox of living with a home haemodialysis machine. Social Work in Health Care, 41(2), 19-35. 
Home Haemodialysis Users' Experience

Gonzalez-Perez, J.G., Vale, L., Stearns, S.C., \& Wordsworth, S. (2005). Hemodialysis for end-stage renal disease: A cost-effectiveness analysis of treatment options. International Journal of Technology Assessment in Health Care, 21(1), 32-39.

Hagren, B., Pettersen, I., Severinsson, E., Lützén, K., \& Clyne, N. (2001). The haemodialysis machine as a lifeline: Experiences of suffering from end-stage renal disease. Journal of Advanced Nursing, 34, 196-202.

Hagren, B., Pettersen, I.A., Severinsson, E., Lützén, K., \& Clyne, N. (2005).

Maintenance haemodialysis: Patients' experiences of their life situation. Journal of Clinical Nursing, 14, 294-300.

Kimmel, P. (2001). Psychosocial factors in dialysis patients. Kidney International, 59, $1599-1613$

Kimmel, P.L., \& Peterson, R.A. (2005). Depression in end-stage renal disease patients treated with hemodialysis: Tools, correlates, outcomes, and needs. Seminars in Dialysis, 18(2), 91-97.

Lehoux, P. (2004). Patients' perspectives on high-tech home care: a qualitative inquiry into the user-friendliness of four technologies. BMC Health Services Research, 4,28 .

Lindqvist, R. \& Sjödén, P-O. (1998). Coping strategies and quality of life among patients on continuous ambulatory peritoneal dialysis (CAPD). Journal of Advanced Nursing, 27(2), 312-319.

Masterson, R. (2008). The advantages and disadvantages of home hemodialysis. Hemodialysis International, 12(Suppl. 1), S16-S20.

Mowatt, G., Vale, L., \& MacLeod, A. (2004). Systematic review of the effectiveness of home versus hospital or satellite unit hemodialysis for people with end-stage 
Home Haemodialysis Users' Experience

renal failure. International Journal of Technology Assessment in Health Care, 20(3), 258-268.

Nagle, L.M. (1998). The meaning of technology for people with chronic renal failure. Holistic Nursing Practice, 12(4), 78-92.

National Institute for Clinical Excellence. (2002). Guidance on home compared with hospital haemodialysis for patients with end-stage renal failure. Technology Appraisal Guidance - No.48. London: National Institute for Clinical Excellence. Retrieved October 12, 2007 from http://www.nice.org.uk/ page.aspx?o=TA048guidance

Polaschek, N. (2003a). Living on dialysis: Concerns of clients in a renal setting. Journal of Advanced Nursing, 41(1), 44-52.

Polaschek, N. (2003b). The experience of living on dialysis: A literature review. Nephrology Nursing Journal, 30(3), 303-309.

Polaschek, N. (2005). Haemodialysis at home: The client experience of self-treatment. Edtna/Erca Journal, 31(1), 27-30.

Reid, K., Flowers, P., \& Larkin, M. (2005). Exploring lived experience. The Psychologist, 18(1), 20-23.

Royal College of Physicians (2007). The changing face of renal medicine in the UK: The future of the specialty. Report of a Working Party. London: Royal College of Physicians. Retrieved April 28, 2009, from http://www.rcplondon.ac.uk/ pubs/contents/64dc39e3-a2e9-40bfa57f69a10a3fc0f3.pdf

Salmon, P., \& Hall, G.M. (2003). Patient empowerment and control: A psychological discourse in the service of medicine. Social Science \& Medicine, 57, 1969-1980. Salmon, P., \& Hall, G.M. (2004). Patient empowerment or the emperor's new clothes. Journal of the Royal Society of Medicine, 97, 53-56. 
Home Haemodialysis Users' Experience

Smith, J.A. (1996). Beyond the divide between cognition and discourse: Using interpretative phenomenological analysis in health psychology. Psychology \& Health, 11, 261-271.

Smith. J.A. (2004). Reflecting on the development of interpretative phenomenological analysis and its contribution to qualitative research in psychology. Qualitative Research in Psychology, 1, 39-54.

Smith, J.A., \& Osborn, M. (2003). Interpretative phenomenological analysis. In J.A. Smith (Ed.). Qualitative Psychology: A Practical Guide to Research Methods (pp. 51-80). London: Sage.

Stuempges, C. (2006). Dialysis: A love/hate relationship? NxStage machine leads to attitude change for one patient. Nephrology News and Issues, 20(11), 54.

Tanyi, R.A., \& Werner, J.S. (2008a). Women's experience of spirituality within endstage renal disease and hemodialysis. Clinical Nursing Research, 17(1), 32-49.

Tanyi, R.A., \& Werner, J.S. (2008b). Toward a trajectory of adjustment in women with end-stage renal disease on haemodialysis. Journal of Nursing and Healthcare of Chronic Illness in association with Journal of Clinical Nursing, 17(5a), 43-50.

Tims, S., King, L. \& Bennet, P.N. (2007). Empowerment for people with end stage renal disease: A literature review. Renal Society of Australasia Journal, 3(2), $52-58$.

Tsay, S.L, \& Hung, L.O. (2004). Empowerment of patients with end-stage renal disease: A randomized controlled trial. International Journal of Nursing Studies, 41(1), 59-65. 
Home Haemodialysis Users' Experience

UK Renal Association (2007). Clinical practice guidelines for haemodialysis (4th ed.). Glasgow, UK: Dr Robert Mactier. Retrieved July 15, 2008, from http://www.renal.org/guidelines/print/HDfinal050207.pdf.

Wallerstein, N. (2006). What is the evidence on effectiveness of empowerment to improve health? Copenhagen: WHO Regional Office for Europe (Health Evidence Network report). Retrieved April 27, 2009, from http://www.euro. who.int/Document/E88086.pdf

Walton, J. (2002). Finding a balance: A grounded theory study of spirituality in hemodialysis. Nephrology Nursing Journal, 29(5), 447-457.

Weintraub, J. (2004). A freedom still worth fighting for. Nephrology News and Issues, 18(3), 30-32.

Willig, C. (2001). Introducing Qualitative Research in Psychology: Adventures in Theory and Method. Buckingham: Open University Press. 